\title{
INTERCONEXÃO, POLARIZAÇÃO E PODER DOS DADOS: DESAFIOS E OPORTUNIDADES PARA A FILANTROPIA
}

\author{
Renato Guimarães
}

\section{// resumo}

As novas formas de captura, organização e distribuição dos processos comunicativos, catapultadas pelas tecnologias digitais, abriram espaço para formatos diretos de mobilização e engajamento que estão modificando as estruturas de poder político e econômico. Em consequência, estamos assistindo a um aumento da polarização política e social, alimentada pelas fake news. Outro aspecto é a relevância crescente dos dados gerados pelas diversas interações digitais. Este artigo discute como a filantropia pode fazer frente aos desafios e oportunidades gerados por esse contexto, a fim de se adequar às crescentes demandas por mais transparência, eficiência, eficácia e melhor mensuração de impacto, além de reconhecer e atender a demandas de audiências mais segmentadas e conscientes de suas necessidades e valores específicos.

Palavras-chave: filantropia | investimento social privado | data philanthropy | fake news | transformação digital. 


\section{OS ARTIGOS GIFE}

A série Artigos GIFE publica reflexões e análises de pesquisadores brasileiros de diferentes áreas do saber com o objetivo de estimular, ampliar e disseminar a produção de conhecimento qualificado sobre o campo da filantropia, do investimento social privado e da sociedade civil no Brasil.

A partir da premissa de que a produção de conhecimento sobre esses temas tem um papel fundamental na expansão, diversificação e qualificação da ação pública pela sociedade, a iniciativa também pretende contribuir para ampliar as conexões entre o setor, as universidades e os centros de pesquisa, promovendo e apoiando o envolvimento de novos atores com a temática e a circulação ampliada de ideias em torno dela.

Este texto integra a terceira edição dos Artigos GIFE, que propõe a publicação mensal de artigos selecionados por meio de chamada pública e convite a autores especialistas em temáticas específicas e relevantes para o setor, buscando apoiar e fomentar a produção de conhecimento sobre o investimento social no Brasil.

\section{O GIFE}

O Grupo de Institutos Fundações e Empresas (GIFE) é uma organização sem fins lucrativos que reúne associados de origem empresarial, familiar ou independente que investem em projetos de interesse público. Criado em 1989 como grupo de troca e colaboração e institucionalizado em 1995 por 25 organizações, tornou-se referência no campo da filantropia e do investimento social privado no Brasil.

Nesses mais de 20 anos de atuação, tem contribuído para o fortalecimento de práticas e ações a serviço do bem comum no país, trabalhando para expandir, qualificar e fortalecer o investimento social privado, diversificar e ampliar atores e recursos, criando referências e estimulando boas práticas de gestão, bem como articulando o setor com a sociedade e a agenda pública. Atualmente, o GIFE reúne mais de 150 associados que, somados, aportam mais de R\$ 3 bilhões por ano em projetos próprios e no apoio a projetos de terceiros. 


\section{artigos \\ GIFE}

\section{INTRODUÇÃO}

A palavra filantropia, até não muito tempo atrás, tinha, no Brasil, uma certa conotação negativa em muitos setores da sociedade. Era associada à caridade, à manutenção do status $q u o$, a atividades escusas ou pouco transparentes. Traduzia-se, muitas vezes, em práticas pouco profissionais, quando não francamente corruptas, ou que serviam a interesses políticos ou religiosos particulares. Mais recentemente, o papel da filantropia vem sendo rediscutido, a partir, especialmente, de um maior profissionalismo do setor. O Brasil está longe ainda dos países de forte tradição filantrópica, especialmente Estados Unidos e Europa, mas progressos têm sido feitos no sentido de ampliar as possibilidades de exercer o "amor à humanidade", sentido grego original da palavra filantropia.

Neste artigo, vamos abordar alguns desafios e oportunidades para a filantropia no limiar de um tempo de transformações profundas, aceleradas pela emergência dos processos e tecnologias de comunicação digital. Na primeira parte, vamos entender como abordagens diversas para a filantropia contribuíram, ao longo do século XX, para uma maior profissionalização do setor, especialmente nos Estados Unidos, influenciando outros contextos nacionais, incluindo o Brasil.

Em seguida, vamos discutir como a emergência de novas formas de exercício do poder, tornadas possíveis e estimuladas pelas mídias digitais, impactam o modo como as pessoas se conectam entre si e, portanto, a maneira como influenciam tomadores de decisão, incluindo o campo da filantropia.

Um dos resultados desse novo momento de constante interconexão é o aumento da polarização na sociedade, catapultado pelo fenômeno das fake news. Em consequência, como mostramos no capítulo seguinte, há um aumento da pressão sobre atores do campo filantrópico por mais transparência e claridade sobre suas posições públicas em temas importantes, como direitos humanos, mudanças climáticas e diversidade.

Finalmente, colocamos uma lupa sobre uma tendência muito importante, a data philanthropy. Ou seja, o compartilhamento aberto dos dados gerados pelas diversas organizações que atuam no setor da filantropia de forma a produzir e estimular melhores práticas e um entendimento mais profundo sobre o impacto efetivo das ações para a sociedade. 


\section{FILANTROPIA EM NÜMEROS}

Em um livro autobiográfico publicado em 1909, o magnata do petróleo John D. Rockefeller tratou de definir a "melhor filantropia" como aquela que traz os maiores benefícios e causa os menores danos, traduzindo-se na alocação de recursos (esforço, tempo, dinheiro) para empregar as pessoas com salário adequado, expandir e ampliar os recursos disponíveis e "gerar oportunidades de progresso e trabalho saudável onde antes não existiam” (ROCKEFELLER, 1909, p. 142).

Em retrospecto, a visão de Rockefeller permanece atual, na medida em que ele defendia que o trabalho do filantropo acontece em tempo integral e não está dissociado da sua vida cotidiana. Nesse sentido, a filantropia representaria uma visão integral do mundo a partir do impacto potencial da ação proativa pelo bem comum e deveria permear todas as formas de atuação na sociedade. Como ele dizia, "o homem que planeja fazer todas as suas doações [somente] no domingo é um péssimo apoio para as instituições do país” (ROCKEFELLER, 1909, p. 143).

Muitas vezes, a emergência da moderna filantropia está associada à presença e ação dos Barões do Capitalismo de fins do século XIX e começo do XX. Sem dúvida, figuras como o próprio Rockefeller, além de Henry Ford, Cornelius Vanderbilt, Andrew Carnegie - e, antes deles, George Peabody - são emblemáticas da ideia de que a fortuna acumulada (muitas vezes de maneira selvagem) deveria ser devolvida ao público na forma de ações filantrópicas.

Mas o fato é que já no começo do século XX estava bastante consolidada a ideia de que era importante haver esforços organizados e deliberados para arrecadar recursos da sociedade e instituições capazes de distribuílos para causas ou temas relevantes. Organizações até hoje importantes, como a Cruz Vermelha Internacional, nasceram e se consolidaram fundamentalmente com o apoio da transferência de recursos de pessoas físicas ou entidades corporativas privadas.

Ao longo do século XX, portanto, o papel da filantropia como um elemento primordial para responder aos desafios constantes e/ou emergenciais da sociedade se solidificou e se profissionalizou. Os volumes de recursos mobilizados a cada ano cresceram em proporções que nem os primeiros grandes filantropos citados poderiam imaginar. Apenas nos Estados Unidos, em 2018, o total de doações para causas filantrópicas chegou a 427,71 bilhões de dólares (GIVING USA, 2019).

Nesse contexto, a influência que os barões modernos, membros do exclusivo clube dos bilionários, têm na formulação de políticas públicas e na alavancagem de linhas de pesquisa e de ação na sociedade reflete a dos seus antepassados mais famosos. Em 2018, os 50 maiores filantropos americanos doaram cerca de 14,1 bilhões de dólares. Somando-se o total de suas doações durante suas vidas, incluindo as diretas e as feitas por suas fundações e institutos, chega-se a valores acima de 173 bilhões de dólares (FORBES, 2019).

A eles soma-se um fenômeno que se firmou especialmente na segunda metade do século XX: a atuação de corporações diretamente no campo da filantropia, a partir da criação de seus próprios institutos e fundações alinhados às suas estratégias de responsabilidade social e sustentabilidade.

Nos Estados Unidos, em 2018, do total de 427,71 bilhões de dólares doados para a caridade ao longo do ano, corporações foram responsáveis por cerca de $5 \%$ do total, equivalente a 20,7 bilhões, um crescimento de 5,4\% com relação ao ano anterior. Ainda assim, é interessante notar que, nos Estados Unidos, a filantropia é basicamente exercida por indivíduos, responsáveis por cerca de $77 \%$ do total de doações, quando somadas as doações diretas e indiretas, por meio de legado/ herança (GIVING USA, 2019).

No Brasil, o conceito mais abrangente de filantropia encontra, desde 1990, um recorte mais específico, delimitado pela ideia do investimento social privado (ISP). Essa foi a forma como os membros do Grupo de Instituto, Fundações e Empresas (GIFE), uma associação de investidores sociais brasileiros, passou a denominar ações filantrópicas que envolvem repasses voluntários de recursos privados realizados de "forma planejada, monitorada e sistemática a projetos sociais, culturais e ambientais de 


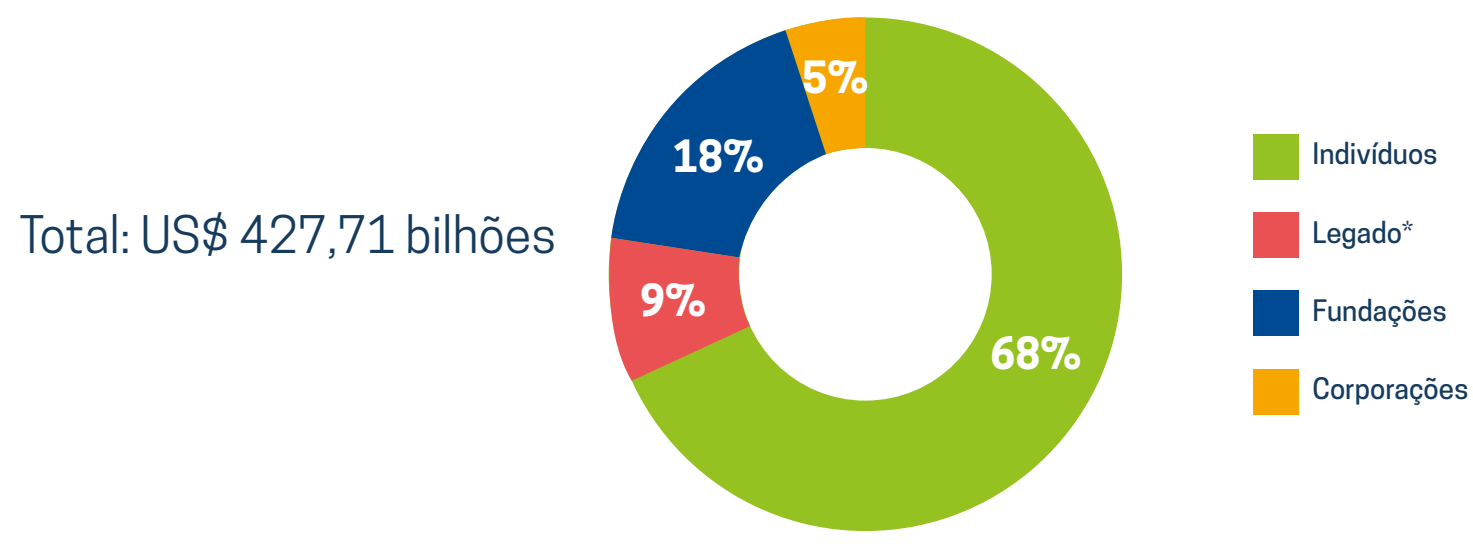

Fonte: Giving USA (2019, p. 21).

Nota: * Legado (bequest, no original) é uma doação feita, como parte de um testamento, para indivíduos ou organizações sem fins lucrativos.

interesse público”. Nelas, estariam incluídas "as ações sociais protagonizadas por empresas, fundações e institutos de origem empresarial ou instituídos por famílias, comunidades ou indivíduos” (GIFE, 2020). Atualmente, há um movimento de aproximação entre os dois termos no Brasil, com a valorização do termo filantropia, sendo ambos usados neste artigo como sinônimos.

Diferentemente dos Estados Unidos, no contexto brasileiro não existem dados consolidados sobre o universo da filantropia ou, mais especificamente, do investimento e dos investidores sociais, que incluam, por exemplo, volumes, destinação ou caraterização de todos os atores. Por exemplo, o dado mais recente de doações de indivíduos é de 2015 (IDIS, 2016).

Desconsiderando as doações de indivíduos e legados (bequest) - que não são foco deste artigo -, a estimativa Giving USA para 2018 foi que fundações e corporações contribuíram com $23 \%$ da filantropia norte-americana, ou seja, em torno de 98 bilhões de dólares. No Brasil, o Censo GIFE é uma das ferramentas que ajudam a ter uma dimensão parcial da contribuição desses atores e aponta, para o mesmo ano, um volume de 3,25 bilhões de reais de seus associados em ações de ISP (GIFE, 2019).

Figura 2 - ISP de organizações respondentes do Censo GIFE 2018 por tipo de investidor, Brasil, 2018

\section{Total: $\mathrm{R} \$ 3,25$ bilhões}

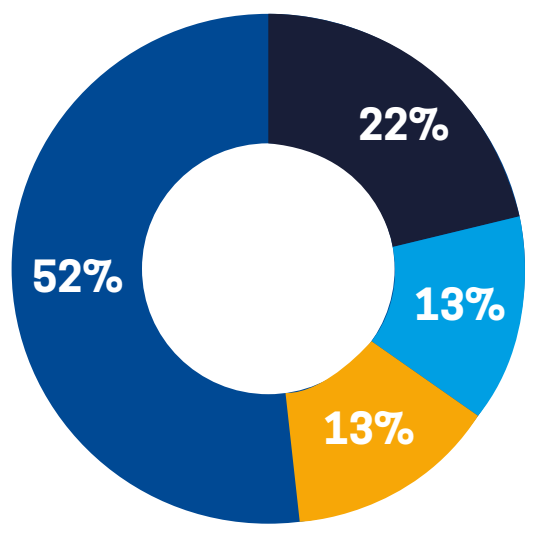

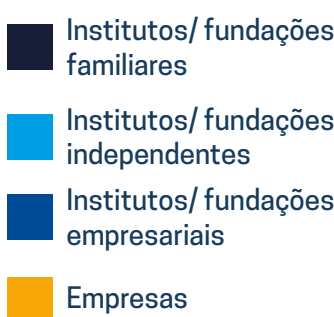

Empresas 
De uma forma geral, como fica evidente nos dados apresentados, o volume e o contexto da filantropia nos Estados Unidos são bem diferentes do Brasil. Ainda assim, os desafios são similares e alguns deles são explorados mais adiante.

\section{OS NOVOS PODERES}

A par do progresso e sofisticação das diversas formas de exercício da filantropia, um novo fenômeno foi se desenhando, especialmente a partir do início dos anos 2000, com a prevalência das novas tecnologias digitais, que ampliaram de forma exponencial o poder de influência dos indivíduos.

Entre os efeitos desse fenômeno estão o aumento significativo das capacidades de geração e alavancagem direta de recursos por parte de indivíduos, assim como o maior poder de escrutínio sobre as organizações e atividades filantrópicas em geral.

Outro aspecto é a geração ininterrupta e exponencial de dados, que pode ajudar as organizações filantrópicas a avaliar, com mais profundidade, o impacto de suas ações e as aproximar do real interesse ou necessidade das pessoas. Esse mesmo fenômeno as expõe, mais do que nunca, aos debates políticos emergentes e às exigências por mais transparência e coerência.

Como isso se dá na prática?

A era em que vivemos, da sociedade interconectada, embute transformações que vão muito além do acesso a tecnologias de captação, registro, análise e transmissão de informação e dados. A forma como as pessoas se relacionam, constroem afinidades de todos os tipos, desconstroem e reconstroem processos políticos, econômicos, sociais e culturais, mudou de uma maneira que mal começamos a entender.

Considerado um dos pais da Internet, o engenheiro Paul Baran recebeu, no início dos anos 1960, o desafio de pensar como os sistemas de comunicação americanos poderiam resistir a um hipotético ataque nuclear soviético. Ele e sua equipe imaginaram, então, um sistema de comunicação distribuída, no qual a informação seria "quebrada" em pequenas partes e redistribuída por todos os nós da rede. Dessa forma, caso algum dos nós fosse afetado, ainda assim a comunicação seguiria fluindo pelo sistema.

\section{Figura 3 - Centralizada, descentralizada e distribuída}
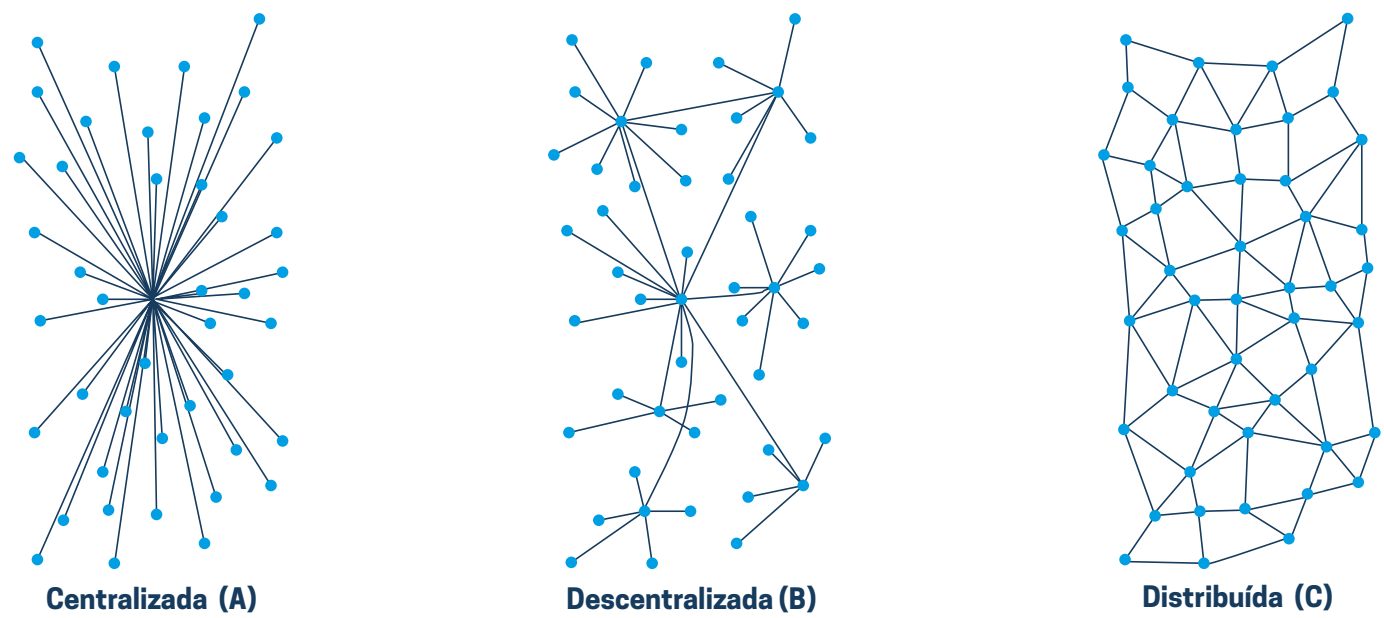

Fonte: Baran (1964, p. 2).

Nota: Original da topografia de redes imaginada por Paul Baran. Os pontos que representam os nós das diferentes configurações de rede ocupam o mesmo espaço nas três figuras, o que muda é a forma como estão interligados. No caso da rede distribuída, caso um ou mais nós da rede sejam inviabilizados, a comunicação segue fluindo pelo sistema. 0 mesmo não pode ser dito das redes centralizada e descentralizada, ambas muito menos resilientes. 
Obviamente, era a emergência conceitual da internet. O que Baran não previu, mesmo porque não era o escopo de seu estudo, é que, com o sistema distribuído, ele estava gerando as bases para recompor a forma mesma de se exercer o poder no mundo. Se antes o controle da informação, dos recursos financeiros, do poder político, dos fundamentos religiosos, passava necessariamente por um mix de sistemas centralizados e descentralizados, com a internet tudo mudou.

Cada nó da rede, ou seja, cada um de nós, temos na ponta dos nossos dedos a capacidade de ressignificar as informações que passam pelas nossas mãos e retransmiti-las para nossas respectivas redes pessoais, com isso influindo no sistema como um todo. Essa é a essência do que alguns teóricos chamam de "novo poder".

Mas em que contexto se dá esse novo poder?

É importante ter em conta que estamos, como nunca na história da humanidade, inundados por informações e estímulos sensoriais. Uma pesquisa da IDC-Seagate mostrou que, em 2020, cada pessoa estará, em média, envolta em 1.426 interações diárias. Para 2025, chegaremos a 4.909 - o que resultará em uma interação digital a cada 18 segundos (REINSEL, GANTZ e RYDNING, 2018, p. 13). Podemos supor que em poucos anos estaremos permanentemente conectados, gerando dados e atuando como hubs de conteúdos diversos.

Uma das consequências diretas desse fenômeno é que ficaremos cada vez mais indiferentes à maioria das mensagens. Portanto, a disputa pela nossa atenção será ferrenha. Conseguir que fiquemos atentos a um simples post de redes sociais será cada vez mais difícil. Obter níveis mais profundos de engajamento será ainda mais complexo.

\section{Figura 4 - Interações digitais por pessoa por dia}

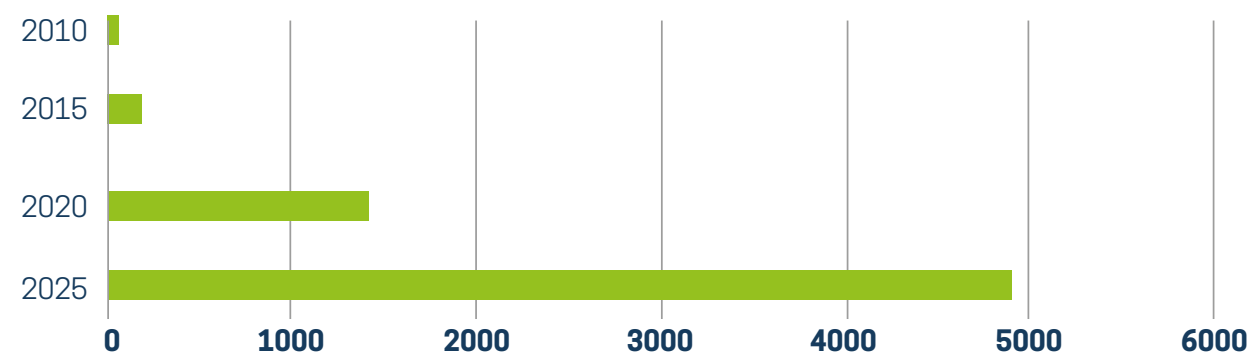

Fonte: Reinsel, Gantz e Rydning (2018).

Voltando ao conceito de novo poder, tal como preconizado por Henry Timms e Jeremy Heimans (2018), a forma tradicional de organização do "velho poder", ainda largamente vigente, está baseada sobretudo em sistemas hierarquizados, criados para controlar os fluxos de informação e de recursos.

No novo poder, o controle passa por uma intermediação crescente e exponencial de atores diversos, especialmente indivíduos, distribuídos no sistema e atuando de forma não-hierarquizada. Não é sem razão que estruturas políticas, econômicas e sociais estejam sendo desafiadas em várias partes do mundo por movimentos e mobilizações aparentemente desestruturados (do ponto de vista do poder tradicional), mas altamente efetivos. Em consequência, abundam experimentos e demandas por governanças informais (em rede), processos colaborativos, compartilhados e de código aberto, transparência radical, valorização da cultura "fazedora" (maker) e do "faça-você-mesmo" (do-it-yoursef) e um compromisso de adesão limitado no tempo e espaço, condicionado aos interesses mais imediatos. 
A "volatilidade" dos gostos e adesões é uma marca desses novos tempos. Como dizia, em 2016, Joshua Topolsky, co-fundador da The Verge e da Vox Media: "Vivemos na era do update, e a geração criada na Internet é a mais inconstante das campeãs de marca: adora algo apaixonadamente, até que deixa de amar. Então, segue em frente" (TOPOLSKY, 2016).

A mencionada fluidez extrema dos processos sociais e políticos, característica da era de novo poder e de sociedade interconectada em que estamos apenas entrando, traz, portanto, novos e urgentes desafios (e oportunidades) para o modelo tradicional de filantropia. Será preciso se reinventar no contexto de um mundo onde a abundância exponencial de dados abre novas fronteiras de conhecimento e a polarização é crescente.

\section{POLARIZAÇÃO E FAKE NEWS}

A resiliência da democracia tem sido testada, em várias partes do mundo, pela emergência de governos autoritários ou protoautoritários, operando nos limites das regras democráticas a partir de um processo permanente de estiramento das emoções coletivas e fazendo largo uso das formas distribuídas de organização e mobilização. O resultado tem sido um aumento sem precedente nas polarizações diversas (políticas, econômicas, religiosas, morais, sociais), que vem intoxicando e danificando o tecido social construído a duras penas, especialmente após o fim da Segunda Guerra Mundial.

A correlação direta entre a emergência dessas forças políticas e sua capacidade de compreender como se deslocam os interesses coletivos no eterno fluxo do mundo digital têm levado a mudanças sistêmicas abruptas. Entre os operadores dessas mudanças, estariam figuras como os "engenheiros do caos", na descrição crua do escritor italiano Giuliano da Empoli: profissionais de dados e internet que ajudariam, com fake news, teorias de conspiração e algoritmos, a usar o ódio, o medo e o ressentimento para influenciar processos políticos (EMPOLI, 2019).

O pano de fundo seria a oportunidade de punir as elites tradicionais, à esquerda e à direita, que estariam traindo permanentemente a vontade e o mandato populares. Para autores como Empoli, esse novo modo de conduzir o jogo político depende, em grande medida, da permanência da polarização na sociedade e do estiramento constante das emoções coletivas.

Aqueles que declaram que a chama populista durará pouco - pois uma vez no poder, as forças que a encarnam não conseguirão manter suas promessas - estão nadando em plena ilusão. A promessa central da revolução dos populistas é a humilhação dos poderosos, e ela se realiza já no momento em que eles ascendem ao poder (EMPOLI, 2019, p. 834).

Em um mundo de verdades absolutas (ou absolutistas) tendentes aos extremos da sociedade, dificilmente organizações que atuam no espaço público conseguem ficar à margem da polarização. O simples chamado ao entendimento, ou a uma via de centro, encontra um espaço cada vez mais limitado para florescer. E essa conjuntura não demonstra tendência a mudanças radicais nos próximos anos. Antes pelo contrário.

Basta pensar que, no Brasil, segundo estudo apresentado pela ONG Avaaz em audiência da Comissão de Defesa dos Direitos da Mulher da Câmara dos Deputados (AVAAZ, 2019), sete em cada dez brasileiros se informam pelas redes sociais e $62 \%$ já acreditaram em alguma notícia falsa. Pode-se imaginar o que significa para organizações que apoiam temas de saúde pública saber que, segundo outro estudo da Avaaz, feito em parceria com a Sociedade Brasileira de Imunizações (SBIm), 48\% dos entrevistados disseram usar as redes sociais e o WhatsApp como uma das principais fontes de informação sobre vacinas, enquanto $57 \%$ dos que não se vacinaram ou não vacinaram uma criança usaram alguma justificativa considerada incorreta pela SBIm e/ou pela Organização Mundial da Saúde. Por exemplo, o alegado risco de as vacinas causarem efeitos colaterais graves ou o argumento de não serem realmente necessárias (AVAAZ, 2019). 
É nesse contexto que filantropos, organizações que atuam nos campos da filantropia e ISP e mesmo empresas em suas ações de responsabilidade social e sustentabilidade serão cada vez mais chamados a se posicionar sobre os mais diversos temas públicos e questionados - e diretamente atacados - pelos polos políticos contrários.

Um artigo de 2014 publicado pela Stanford Social Innovation Review já apontava para esse dilema ético e político e decretava que "os dias em que grandes fundações poderiam permanecer acima da briga partidária, mesmo quando estavam profundamente engajadas na defesa de mudanças nas políticas públicas, praticamente já se foi” (TELES, HURLBURT e SCHMITT, 2014). E isso antes ainda da eleição de Donald Trump para a presidência dos Estados Unidos e do movimento mais amplo que levou várias lideranças nacionalistas-conservadoras ao poder em diferentes países.

Se a equidistância não é mais possível e pode ser motivo, por si só, para mais ataques à imagem e reputação das organizações, como manobrar nesse contexto? Como responder ao chamado por mais transparência em um contexto no qual a Verdade, como elemento fundamental de credibilidade, é esgarçada e desacreditada sob o império das fake news?

O artigo da Stanford Social Innovation Review indica três possíveis rotas para os atores filantrópicos seguirem nesse contexto adverso:

- manter o curso habitual de buscar mudanças por meio de pesquisa rigorosa e validação de atores sociais "neutros";

- tentar mudar o sistema - apoiando iniciativas que minimizem ou controlem as ferramentas ou canais que estimulam a polarização;

- aceitar a nova realidade - e tentar navegar dentro dela, adotando modelos de mudança política que funcionem no novo contexto (TELES, HURLBURT e SCHMITT, 2014).

Seja como for, para os autores do artigo, em algum momento será preciso aceitar a necessidade de orientar os recursos e a atuação filantrópica na direção clara de algum polo, assumindo essa decisão de forma transparente e aberta. Se o foco de atuação filantrópica é no campo da saúde, educação, direitos humanos, meio ambiente, fortalecimento da sociedade civil, diversidade, para mencionar alguns, não haverá mais muito espaço para hesitar na defesa clara dos interesses coletivos e se contrapor à ameaça desses direitos.

\section{A EMERGÊNDIA DA DATA PHILANTHROPY}

Outra decorrência do mundo interconectado em que estamos vivendo é a produção massiva e exponencial de dados. Para se ter uma ideia, em um único dia 500 milhões de Tweets e 294 bilhões de e-mails são enviados, 65 bilhões de mensagens são compartilhadas no WhatsApp e cinco bilhões de procuras são realizadas no Google (WORLD ECONOMIC FORUM, 2019).

Não é sem razão que a Organização das Nações Unidas (ONU) fala em uma "revolução dos dados" e defende o aumento da capacidade de organizações, empresas e governos em usar os dados para aumentar o impacto social de suas ações. De fato, já em 2014 um grupo de trabalho da ONU chamou a atenção para a urgência do tema de uma forma muito direta:

Novas tecnologias estão levando a um aumento exponencial no volume e nos tipos de dados disponíveis, criando possibilidades sem precedentes para informar e transformar a sociedade. [...] Mas muitas pessoas, organizações e governos são excluídos [do novo mundo dos dados] por falta de recursos, conhecimento, capacidade ou oportunidade. Existem enormes e crescentes desigualdades no acesso a dados e informações e na capacidade de usá-los (IEAG, 2014).

É nesse contexto que o conceito de data philanthropy vem crescendo e ganhando corpo. Parte da premissa 
de que os dados gerados em operações corporativas, sociais, filantrópicas ou governamentais podem e devem ser compartilhados, dentro de parâmetros éticos e legais, a fim de maximizar os impactos de projetos e ações em benefício público. Por exemplo, dados agregados gerados pelas redes móveis da empresa Telefonica-Vivo, correlacionados com informações obtidas de sensores de qualidade do ar e de tráfego, estão ajudando a prefeitura de São Paulo a prever, com antecipação de 24 a 48 horas, um aumento nos níveis de poluição do ar. Assim, as autoridades podem tomar medidas preventivas caso as emissões de poluentes atmosféricos comprometam a saúde humana.

Esse tipo de ação colaborativa de dados ainda está engatinhando, mas aponta para futuro imediato promissor. Em seu estudo sobre data philanthropy, o Urban Institute indica alguns benefícios tangíveis do compartilhamento de dados em empresas que, ao demonstrarem sua disponibilidade e boa cidadania, melhoram seu posicionamento e visibilidade. Mais do que isso, acaba sendo uma maneira de a empresa colaborar efetivamente para aumentar a compreensão sobre questões sociais que exigem soluções multissetoriais, além de ajudar a desencadear inovações e mitigar riscos para o negócio (URBAN INSTITUTE, 2018).

Evidentemente, a privacidade dos dados segue sendo um tema capital, que ficará ainda mais relevante com a entrada em vigor da Lei Geral de Proteção de Dados, prevista para agosto de 2020. A nova legislação é mais rigorosa quanto à captura, manuseio e compartilhamento de dados, o que ajuda a definir de forma mais clara os limites e possibilidades da data philanthropy no Brasil, a partir do uso de dados agregados, que impedem a identificação individualizada.

Um outro aspecto especialmente relevante para as organizações atuando no setor filantrópico e de ISP é o desenvolvimento de suas capacidades a fim de se tornarem organizações data driven. Ou seja, de desenvolverem uma cultura interna orientada por dados, que vá além da coleta e distribuição, que os incorpore aos processos de planejamento, implementação e avaliação de impacto.

\section{Quadro 1 - Cinco competências principais de uma organização ou empresa para se tornar fluente em dados}

1 Incorporar uma cultura analítica que permita avaliar e tomar decisões baseada em evidências e insights

1 (ideias, percepções, conclusões) gerados por dados.

2 Investir na coleta efetiva de dados, tendo em conta padrões éticos e legais.

3 Desenvolver a capacidade de analisar os dados recolhidos e transformá-los em informação relevante e estratégica.

4 Implementar processos decisórios orientados por dados e com um propósito explícito de impactar positivamente a sociedade.

5 Transformar as informações e insights gerados pela análise de dados em narrativas mobilizadoras e relevantes para stakeholders e sociedade em geral.

Fonte: Adaptado de Andrade (2019).

A data philanthropy surge também como uma oportunidade de as organizações que atuam no setor filantrópico coordenarem suas produções de dados individuais a fim de maximizar a capacidade analítica gerada pela combinação dessas informações. Estudos e pesquisas gerados anualmente pelas diferentes organizações que atuam ou têm interesse na filantropia e ISP deveriam se coordenar e ter elementos comuns que permitissem uma análise transversal dos dados levantados.

Mais impactante, ainda que desafiador do ponto de vista de recursos, seria estabelecer uma plataforma comum de acesso aos dados gerados pelas diferentes organizações. No Brasil, um avanço nessa direção foi 
dado pelo GIFE em 2019, com o lançamento do Mosaico, um portal de dados sobre investimento social que disponibiliza de forma aberta as bases de dados do Censo GIFE 2018 e oferece uma sessão com pesquisas, publicações e plataformas de dados de outras organizações do setor. Outro exemplo é o Mapa das Organizações da Sociedade Civil, uma iniciativa do Instituto de Pesquisa Econômica Aplicada (IPEA) que reúne, de forma colaborativa, dados abertos de todo o Brasil sobre organizações da sociedade civil.

Um desafio, no caso brasileiro, é justamente caminhar para desenvolver uma plataforma aberta, reunindo dados gerados pelas diferentes organizações. Uma possível referência é a base de dados sobre filantropia oferecida pelo Foundation Center, que permite, inclusive, o uso de application programming interfaces (API) para ligar as informações obtidas a websites, intranets ou outros programas.

\section{CONSIDERAÇÕES FINAIS}

A democracia tem demonstrado uma capacidade de resiliência, apesar dos constantes ataques sofridos ao longo dos anos. Neste momento, o novo ambiente de interconexão digital permanente traz ferramentas que podem tanto fortalecê-la quanto enfraquecê-la, como temos assistido.

No ambiente nebuloso e envenenado das fake news, os valores da democracia devem ser mais defendidos do que nunca. A transparência, o foco no bem comum, o respeito às diferenças e a luta contra a desigualdade são alguns dos valores que geram, no longo prazo, sociedades mais sadias e prósperas.

A filantropia, como setor, não escapa dessa contestação generalizada e também é chamada a se posicionar e a demonstrar de forma tangível seu valor para a sociedade. Rhodri Davies, da Charities Aid Foundation, expõe o tema de forma muita aguda:

Tendo em vista o aumento global do populismo, a filantropia é frequentemente vista como parte do problema. Há uma falta de transparência em torno de onde o dinheiro vem e uma crítica crescente a elites que criam sistemas autoperpetuadores de poder e influência (DAVRIES, 2019, p. 13).

O que pode parecer um risco, na verdade é uma grande oportunidade. As novas ferramentas digitais, especialmente a cultura de dados, podem ser um canal extraordinário para aumentar a transparência no uso dos recursos e no impacto alcançado, ajudando a minimizar eventuais críticas e ataques.

Mais do que isso, podem ajudar as organizações que atuam no setor da filantropia tradicional ou, mais especificamente, desenvolvem ações de ISP, a criar uma conexão mais profunda e dinâmica com os stakeholders, compreendendo e antecipando macrotendências e gerando canais de mobilização e comunicação que permitam um engajamento real com os beneficiários e com a sociedade como um todo.

Trata-se, efetivamente, de compreender na sua essência a nova realidade de organização do poder e tirar o melhor proveito disso para fortalecer a democracia e trazer mais benefícios para a coletividade. 


\section{REFERÊNCIAS BIBLIOGRÁFICAS}

ANDRADE, Carol. Cinco competências para uma organização fluente em dados. Social Good Brasil, 24 set. 2019. Disponível em: 〈http://socialgoodbrasil.org.br/2019/09/24/5-competencias-para-uma-organizacao-fluente-em-dados/>. Acesso em: 02 de dez. de 2019

AVAAZ. As fake news estão nos deixando doentes? nov. 2019. Disponível em: https://sbim.org.br/images/files/po-avaazrelatorio-antivacina.pdf. Acesso em: nov. 2019.

AVAAZ. Por que combater a desinformação: impacto e soluções. Apresentação da Avaaz na audiência pública da Comissão de Defesa dos Direitos das Mulheres da Câmara dos Deputados. Brasília: Câmara dos Deputados, 26 nov. 2019, 1:14:09, son., color. Disponível em: https://www.camara.leg.br/evento-legislativo/58659. Acesso em: 27 nov. 2019.

BARAN, Paul. On distributed communications: I. Introduction to distributed communications networks. California: Rand Corporation, 1964. Disponível em: <https://www.rand.org/pubs/research_memoranda/RM3420.html>. Acesso em: 2 dez. 2019.

DAVRIES, Rhodri. Why philanthropy can't afford to ignore AI. In: Foundation horizon scan: taking the long view. Nov. 2019. Disponível em: 〈https://media.nesta.org.uk/documents/Future_Foundations_Provocations.pdf>. Acesso em: 5 dez. 2019.

EMPOLI, Giuliano da. Os engenheiros do caos. São Paulo: Vestígio, 2019. Versão Kindle.

FORBES. America's top 50 givers: meet the philanthropists who gave away the most money in 2018. Estados Unidos, 20 de nov. de 2019. Disponível em: <https://www.forbes.com/top-givers/\#1709103b66ff>. Acesso em: 26 de nov. de 2019.

GIFE. Censo Gife 2018. Disponível em <https://sinapse.gife.org.br/download/censo-gife-2018>. Acesso em: 27 nov. 2019.

GIFE. Investimento social privado. [2020]. Disponível em: 〈https://gife.org.br/investimento-social-privado/>. Acesso em: 17 jan. 2020.

GIVING USA 2019. The annual report on philanthropy for the year 2018. Giving USA Foundation, 2019. Disponível em: <https://lclsonline.org/wp-content/uploads/2019/09/GUSA-2019-AnnualReport.pdf〉. Acesso em: 2 dez. 2019.

HARTNELL, Caroline; MILNER, Andrew Milner. Philanthropy in Brazil: a working paper. Philanthropy for Social Justice and Peace. Mai. 2018. Disponível em: <https://www.sdgphilanthropy.org/system/files/2019-07/PHILANTHROPY-IN-BRAZIL. pdf>. Acesso em: 2 dez. 2019.

IDIS - Instituto para o Desenvolvimento do Investimento Social. Pesquisa doação Brasil 2015. 2016. Disponível em: https:// idis.org.br/pesquisadoacaobrasil/wp-content/uploads/2016/10/PBD_IDIS_Sumario_2016.pdf. Acesso em: jan. 2020.

IEAG - United Nations Secretary-General's Independent Expert Advisory Group on a Data Revolution for Sustainable Development. A world that counts: mobilising the data revolution for sustainable development. 2014. Disponível em: <https:// www.undatarevolution.org/wp-content/uploads/2014/12/A-World-That-Counts2.pdf>. Acesso em: 2 dez. 2019.

REINSEL, David; GANTZ, John; RYDNING, John. The digitization of the world: from edge to core. IDC-Seagate, 2018. Disponível em: <https://www.seagate.com/files/www-content/our-story/trends/files/idc-seagate-dataage-whitepaper.pdf>. Acesso em: 26 nov. 2019.

ROCKEFELLER, John D. Random reminiscences of men and events. New York: Doubleday, Page \& Company, 1909. Disponível em: <http://www.gutenberg.org/ebooks/17090>. Acesso em: 2 dez. 2019.

TELES, Steven Teles, HURLBURT, Heather, SCHMITT, Mark Schmitt. Philanthropy in a time of polarization. Stanford Social Innovation Review. v. 12, n. 3, Summer 2014. Disponível em: https://ssir.org/articles/entry/philanthropy_in_a_time_of_ polarization\#. Acesso em: nov 2019.

TIMMS, Henry; HEIMANS, Jeremy. O novo poder: como disseminar ideias, engajar pessoas e estar sempre um passo à frente em um mundo hiperconectado. Rio de Janeiro: Intrínseca, 2018.

TOPOLSKY, Joshua. The end of Twitter. The New Yorker. 29 jan. 2016. Disponível em: <https://www.newyorker.com/tech/ annals-of-technology/the-end-of-twitter>. Acesso em: 2 dez. 2019.

URBAN INSTITUTE. Data philanthropy: unlocking the power of private data for public good. jul. 2018. Disponível em: 〈https://www.urban.org/research/publication/data-philanthropy-unlocking-power-private-data-public-good/view/full_report>. Acesso em: 1 dez. 2019.

WORLD ECONOMIC FORUM. How much data is generated each day? 17 abr. 2019. Disponível em: <https://www.weforum. org/agenda/2019/04/how-much-data-is-generated-each-day-cf4bddf29f/>. Acesso em: 2 dez. 2019. 


\section{O AUTOR}

\section{Renato Guimarães nato.guima@gmail.com}

Country Director da Global Citizen Year no Brasil. Tem acumulados mais de 20 anos de trabalho em comunicação estratégica e campanhas de mobilização pública em causas de impacto social, em organizações como Greenpeace, IFC/ Banco Mundial, Purpose, Oxfam GB, Instituto Akatu. É jornalista com mestrado em relações internacionais pela Fletcher School of Law and Diplomacy e pós-graduado em comunicação corporativa pela Universidad de Lima. É senior fellow do Center on Philanthropy and Civil Society da City University of New York e fellow do Social Good Brasil. 


\title{
artigos GIFE
}

Supervisão: José Marcelo Zacchi e Gustavo Bernardino

Coordenação: Carolina Magosso

Produção editorial: Gleice Regina Guerra

Apoio: Graziela Santiago

Diagramação: Clarissa Sitó

Impressão: Forma Certa

ISSN: 2674-8061

DOI: 10.33816/gife.20200201a1

(c) 2020 GIFE - Grupo de Institutos Fundações e Empresas

\section{(c) (P) 8}

Este material é disponibilizado sob a licenca Creative Commons Atribuição Não Comercial 4.0 Internacional. http://creativecommons.org/licenses/by-nc/4.0

As opiniões e análises expressas nesta publicação não necessariamente refletem as do GIFE.

\author{
Apoio institucional \\ Ford Foundation \\ Fundação Lemann \\ Instituto Unibanco \\ Laudes Foundation
}

QGIFE 